\title{
Perbedaan Tingkat Kecemasan Berdasarkan Jenis Kelamin pada Tindakan Penumpatan Gigi
}

\author{
${ }^{1}$ Fazriah F. Paputungan \\ ${ }^{1}$ Paulina N. Gunawan \\ ${ }^{2}$ Damajanty H. C. Pangemanan \\ ${ }^{1}$ Johanna A. Khoman \\ ${ }^{1}$ Program Studi Pendidikan Dokter Gigi Fakultas Kedokteran \\ ${ }^{2}$ Bagian Fisiologi Fakultas Kedokteran \\ Universitas Sam Ratulangi Manado \\ Email: lilypaputungan@gmail.com
}

\begin{abstract}
Oral and dental treatment is considered to be scary that can causes anxiety. Gender is one of the factors that influence the anxiety due to restorative treatment especially in dental caries. This study was aimed to determine the difference in anxiety level based on gender in restorative treatment at RSGM Unsrat. This was an analytical study using a cross sectional design. Samples were obtained by using purposive sampling method. Levels of anxiety in males and females were measured by using questionnaire that had been tested for validity. The results showed 32 patients aged 18-65 years who received dental restorative treatment in year 2019 at RSGM Unsrat. Males were as many as females. The levels of anxiety due to the restorative treatment were as follows: not anxious $(31.2 \%)$, mild $(40.7 \%)$, moderate $(28.1 \%)$, severe $(0.0 \%)$, and very severe $(0.0 \%)$. The unpaired $t$-test showed a p-value 0.000 . In conclusion, there were differences in male and female anxiety levels due to restorative treatment at RSGM Unsrat; females were more anxious than males.
\end{abstract}

Keywords: anxiety level, gender, restorative treatment

\begin{abstract}
Abstrak: Pengobatan penyakit gigi dan mulut masih kurang diminati masyarakat karena dianggap menakutkan sehingga dapat menimbulkan kecemasan. Jenis kelamin merupakan salah satu faktor yang dapat memengaruhi kecemasan pada penumpatan gigi yang digunakan terutama pada karies gigi. Penelitian ini bertujuan untuk mengetahui perbedaan tingkat kecemasan berdasarkan jenis kelamin pada tindakan penumpatan gigi di RSGM Unsrat. Jenis penelitian ialah analitik dengan desain potong lintang dan menggunakan teknik purposive sampling. Tingkat kecemasan pada laki-laki dan perempuan diukur berdasarkan kuesioner pengukuran tingkat kecemasan yang telah teruji validitasnya. Pasien yang menerima tindakan penumpatan gigi di RSGM Unsrat berusia 18-65 tahun pada tahun 2019 berjumlah 32 orang dengan jumlah yang sama besar untuk kedua jenis kelamin. Hasil penelitian menunjukkan bahwa yang mengalami kecemasan pada tindakan penumpatan gigi kategori tidak cemas $(31,2 \%)$, ringan $(40,7 \%)$, sedang $(28,1 \%)$, berat $(0,0 \%)$, dan sangat berat $(0,0 \%)$. Hasil analisis bivariat menggunakan uji statistik uji $t$ tidak berpasangan menunjukkan nilai $\mathrm{p}=0,000$. Simpulan penelitian ini ialah terdapat perbedaan tingkat kecemasan antara laki-laki dan perempuan pada tindakan penumpatan gigi di RSGM Unsrat. Kecemasan lebih banyak didapatkan pada perempuan.
\end{abstract}

Kata kunci: tingkat kecemasan, jenis kelamin, penumpatan gigi

Kesehatan gigi dan mulut merupakan salah satu faktor yang melatarbelakangi status kesehatan masyarakat di tingkat nasional, provinsi, dan kabupaten/kota di Indonesia. Masalah kesehatan gigi dan mulut di Indonesia masih menjadi masalah nasional 
yang perlu mendapat perhatian. Hal ini dibuktikan berdasarkan laporan hasil Riset Kesehatan Dasar (Riskesdas) tahun 2018 prevalensi nasional masalah gigi dan mulut yaitu sebesar $57,6 \%$, termasuk karies gigi. ${ }^{1}$

Pengobatan atau perawatan yang dapat dilakukan untuk merawat kerusakan gigi terutama pada karies gigi yaitu dengan tindakan penumpatan gigi. Tindakan pengobatan atau perawatan mulut masih kurang diminati masyarakat karena dianggap menakutkan yang dapat menimbulkan kecemasan berlebih pada penderita.

Kesulitan menangani pasien dalam hal perawatan gigi tidak hanya dalam prosedur teknis perawatan tetapi juga dalam menangani gangguan emosional yang berbedabeda. Pengalaman terdahulu yang dialami pasien seperti tindakan pencabutan yang menyakitkan, jumlah biaya yang mahal, pengalaman masa lalu saat berkunjung ke dokter gigi, atau perasaan cemas ketika instrumen penumpatan dimasukkan ke dalam rongga mulut saat tindakan penumpatan gigi menjadi salah satu faktor yang membuat pasien takut untuk berkunjung ke dokter gigi. ${ }^{2}$ Peningkatan kecemasan yang nyata pada pasien dapat segera teridentifikasi sebelum prosedur dimulai.

Hasil penelitian sebelumnya yang dilakukan oleh Kandou et $\mathrm{al}^{3}$ mengenai gambaran tingkat kecemasan pasien umur dewasa pra pencabutan gigi di Balai Pengobatan Rumah Sakit Gigi dan Mulut Manado, menyatakan bahwa kategori usia dan jenis kelamin seseorang turut memengaruhi tingkat kecemasan dalam menghadapi ekstraksi gigi. ${ }^{3}$ Golongan usia dewasa muda dan perempuan merupakan pasien yang memiliki tingkat kecemasan tinggi, namun hingga saat ini belum ada penelitian mengenai tingkat kecemasan berdasarkan jenis kelamin pada tindakan penumpatan gigi di Rumah Sakit Gigi dan Mulut Universitas Sam Ratulangi (RSGM Unsrat).

Rumah Sakit Gigi dan Mulut Universitas Sam Ratulangi merupakan satusatunya rumah sakit gigi dan mulut pendidikan di Sulawesi Utara sehingga cukup banyak pasien yang menerima tindakan penumpatan gigi dengan latar belakang yang bervariasi di tempat ini. Berdasarkan uraian di atas maka peneliti tertarik untuk mengetahui perbedaan tingkat kecemasan berdasarkan jenis kelamin pada tindakan penumpatan gigi di RSGM Unsrat.

\section{METODE PENELITIAN}

Penelitian ini dilaksanakan pada bulan Februari-Mei 2019 di RSGM Unsrat yang beralamat di Jalan Dr. Sutomo, Kelurahan Pinaesaan, Kecamatan Wenang, Kota Manado, Provinsi Sulawesi Utara. Jenis penelitian ialah analitik dengan desain studi potong lintang. Populasi penelitian yaitu pasien penumpatan gigi di RSGM Unsrat pada bulan Mei 2019. Teknik pengambilan sampel yang digunakan yaitu purposive sampling dan yang memenuhi kriteria inklusi berjumlah 32 orang pasien.

Pengumpulan data dilakukan melalui wawancara langsung pada responden dengan item pertanyaan pertama dan kedua sebelum dilakukan tindakan, yaitu pada saat pasien duduk di ruang tunggu dan pada saat pasien duduk di kursi gigi. Untuk item pertanyaan kedua sampai seterusnya dilakukan setelah tindakan di bagian konservasi gigi sesuai dengan pertanyaan dan panduan wawancara pada lembar kuesioner yang telah teruji validitasnya. Data yang dikumpulkan yakni nama, jenis kelamin serta usia sesuai dengan kriteria inklusi.

Kuesioner penelitian ini berisi 10 pertanyaan yang berhubungan dengan kecemasan pasien pada tindakan penumpatan gigi yang dibuat oleh peneliti sendiri dan telah diuji validitasnya menggunakan program aplikasi komputer. Kuesioner ini menggunakan skala Likert. Setiap pertanyaan diberi skor 1 bila tidak ada kecemasan; skor 2 bila sedikit cemas; skor 3 bila cemas; skor 4 bila cemas sekali; dan skor 5 bila sangat cemas sekali. Masingmasing skor dijumlahkan dan ditentukan dengan kategori tidak ada kecemasan bila total skor $\leq 10$; kecemasan ringan bila total skor 11-20; kecemasan sedang bila total skor 21-30; kecemasan berat bila total skor 31-40; dan kecemasan sangat berat bila total skor 41-50.

Pengolahan data dilakukan menggu- 
nakan program aplikasi komputer. Analisis univariat digunakan untuk memperoleh gambaran atau deskripsi pada masingmasing variabel dan akan disajikan dalam bentuk tabel distribusi frekuensi. Analisis bivariat menggunakan uji statistik uji $t$ tidak berpasangan untuk menguji perbedaan tingkat kecemasan berdasarkan jenis kelamin pada tindakan penumpatan gigi di RSGM Unsrat.

\section{HASIL PENELITIAN}

Penelitian ini dilaksanakan di RSGM Unsrat yang merupakan satu-satunya rumah sakit gigi dan mulut di Manado. Subjek penelitian ini ialah pasien penumpatan gigi di Bagian Konservasi Gigi berusia 18-65 tahun sebanyak 32 orang.

Tabel 1 menunjukkan distribusi responden berdasarkan usia. Responden terbanyak berusia $18-25$ tahun $(37,5 \%)$ dan yang paling sedikit berusia $56-65$ tahun $(3,1 \%)$. Jumlah responden yang berjenis kelamin laki-laki sama besar dengan jumlah yang berjenis kelamin perempuan, yaitu masingmasing sebesar $50,0 \%$.

Tabel 1. Distribusi responden berdasarkan usia

\begin{tabular}{ccc}
\hline Usia (tahun) & $\mathbf{n}$ & \% \\
\hline $18-25$ & 12 & 37,5 \\
$26-35$ & 9 & 28,2 \\
$36-45$ & 6 & 18,7 \\
$46-55$ & 4 & 12,5 \\
$56-65$ & 1 & 3,1 \\
Total & 32 & 100 \\
\hline
\end{tabular}

Tabel 2 menunjukkan distribusi responden berdasarkan tingkat kecemasan. Dari total 32 reponden, yang memiliki tingkat kecemasan posisi tertinggi yaitu kecemasan ringan $(40,7 \%)$. Selain itu, pada penelitian ini tidak didapatkan tingkat kecemasan kategori berat dan sangat berat.

Tabel 2. Distribusi responden berdasarkan tingkat kecemasan

\begin{tabular}{ccc}
\hline Tingkat kecemasan & $\mathbf{n}$ & $\mathbf{\%}$ \\
\hline Tidak cemas & 10 & 31,2 \\
Ringan & 13 & 40,7 \\
Sedang & 9 & 28,1 \\
Berat & 0 & 0,0 \\
Sangat berat & 0 & 0,0 \\
Total & 32 & 100 \\
\hline
\end{tabular}

Tabel 3 menunjukkan distribusi usia sampel yang mengalami kecemasan, dari 32 reponden penelitian. Yang terbanyak mengalami kecemasan ialah responden berusia 18-25 tahun (91,7\%), diikuti oleh yang berusia $46-55$ tahun (75\%), usia 26-35 tahun (55,6\%), dan usia 36-45 tahun (50,0\%). Responden berusia 56-65 tahun tidak ada yang mengalami kecemasan. Berdasarkan data tersebut, responden yang mengalami kecemasan paling tinggi yaitu yang berusia 18-25 tahun dengan kategori tingkat kecemasan ringan dan sedang sebesar $91,7 \%$.

Tabel 4 menunjukkan perbedaan tingkat kecemasan berdasarkan jenis kelamin pada tindakan penumpatan gigi di RSGM Unsrat.

Tabel 3. Distribusi usia responden yang mengalami kecemasan

\begin{tabular}{cccccccccccc}
\hline \multirow{2}{*}{$\begin{array}{c}\text { Usia } \\
\text { (tahun) }\end{array}$} & \multicolumn{1}{c}{$\begin{array}{c}\text { Tidak } \\
\text { cemas }\end{array}$} & Ringan & Sedang & Berat & \multicolumn{3}{c}{$\begin{array}{l}\text { Sangat } \\
\text { berat }\end{array}$} & Total \\
\cline { 2 - 11 } & $\mathrm{n}$ & $\%$ & $\mathrm{n}$ & $\%$ & $\mathrm{n}$ & $\%$ & $\mathrm{n}$ & $\%$ & $\mathrm{n}$ & $\%$ & $\mathrm{n}$ \\
\hline $18-25$ & 1 & 6,25 & 6 & 50,0 & 5 & 41,7 & 0 & 0,0 & 0 & 0,0 & 12 \\
$26-35$ & 4 & 44,4 & 3 & 33,3 & 2 & 22,2 & 0 & 0,0 & 0 & 0,0 & 9 \\
$36-45$ & 3 & 50,0 & 2 & 33,3 & 1 & 16,7 & 0 & 0,0 & 0 & 0,0 & 6 \\
$46-55$ & 1 & 25,0 & 2 & 50,0 & 1 & 25,0 & 0 & 0,0 & 0 & 0,0 & 4 \\
$56-65$ & 1 & 100 & 0 & 0,0 & 0 & 0,0 & 0 & 0,0 & 0 & 0,0 & 1 \\
\hline
\end{tabular}


Tabel 4. Perbedaan tingkat kecemasan berdasarkan jenis kelamin pada tindakan penumpatan gigi di RSGM Unsrat

\begin{tabular}{lccccccc}
\hline \multirow{1}{*}{$\begin{array}{c}\text { Tingkat } \\
\text { kecemasan }\end{array}$} & \multicolumn{6}{c}{ Laki-laki } & \multicolumn{3}{c}{ Perempuan } & \multicolumn{2}{c}{ Total } & \\
\cline { 2 - 7 } & $\mathrm{n}$ & $\%$ & $\mathrm{n}$ & $\%$ & $\mathrm{n}$ & $\%$ & \\
\cline { 2 - 7 } Tidak cemas & 8 & 50,0 & 2 & 12,5 & 10 & 31,2 & Nilai p \\
Ringan & 8 & 50,0 & 5 & 31,2 & 13 & 40,7 & 0,000 \\
Sedang & 0 & 0,0 & 9 & 56,3 & 9 & 28,1 & \\
Berat & 0 & 0,0 & 0 & 0,0 & 0 & 0,0 & \\
Sangat berat & 0 & 0,0 & 0 & 0,0 & 0 & 0,0 & \\
Total & 16 & 100 & 16 & 100 & 32 & 100 & \\
\hline
\end{tabular}

Hasil analisis uji $t$ tidak berpasangan mendapatkan nilai $\mathrm{p}=0,000 \leq 0,05$, yang menunjukkan adanya perbedaan bermakna antara tingkat kecemasan berdasarkan jenis kelamin pada tindakan penumpatan gigi di RSGM Unsrat.

\section{BAHASAN}

Responden penelitian ini berjumlah 32 orang, terdiri dari 16 orang laki-laki dan 16 orang perempuan (masing-masing sebesar $50,0 \%)$. Hasil wawancara kepada pasien dengan 10 pertanyaan sesuai dengan panduan kuesioner memperoleh pasien yang mengalami kecemasan sebesar $68,8 \%$, yang meliputi tingkat kecemasan ringan $40,7 \%$ dan kecemasan sedang $28,1 \%$ (Tabel 3). Hal ini dapat terjadi karena beberapa faktor yang dapat memengaruhi seseorang mengalami kecemasan, salah satunya karena rasa takut yang muncul dari pikiran sendiri saat seseorang akan menjalani perawatan gigi. Hasil penelitian ini sejalan dengan penelitian yang dilakukan oleh Saatchi et al $^{4}$ di Isfahan, Iran yang mendapatkan sekitar $58,8 \%$ orang mengalami kecemasan dengan perawatan gigi. Hal ini juga selaras dengan penelitian oleh Koleoso et $\mathrm{al}^{5}$ di Nigeria yang menyatakan bahwa sekitar $31 \%$ orang dewasa mengalami rasa takut dan cemas dengan perawatan gigi. Hasil penelitian ini juga didukung oleh Prihastari et $\mathrm{al}^{6}$ di Kepulauan Seribu yang melaporkan bahwa sekitar $85 \%$ orang mengalami kecemasan dengan perawatan.

Hasil distribusi responden berdasarkan usia memperlihatkan responden berusia 18-
25 tahun mempunyai jumlah terbanyak yaitu sebesar 37,5\% (Tabel 1). Distribusi usia responden yang mengalami kecemasan memperlihatkan bahwa jumlah yang mengalami tingkat kecemasan terbanyak berada pada kelompok usia 18-25 tahun $(91,7 \%)$ (Tabel 4). Hasil penelitian ini selaras dengan penelitian yang dilakukan oleh Shresta et $\mathrm{al}^{7}$ di Rumah Sakit Pendidikan di Manglore, India yang mendapatkan bahwa kecemasan perawatan gigi lebih terlihat pada usia yang lebih muda. Hal yang serupa juga dilaporkan oleh Boky et $\mathrm{al}^{8}$ di Manado yang mendapatkan tingkat kecemasan yang paling tinggi berada pada kelompok usia 18-40 tahun. Hal ini terjadi karena usia turut memengaruhi kecemasan seseorang. Gangguan kecemasan lebih mudah dialami oleh seseorang yang berusia lebih muda dibandingkan dengan yang berusia lebih tua. ${ }^{9}$ Usia muda lebih mudah terkena tekanan (stres) psikologis dan cemas, karena kesiapan mental dan jiwa yang belum matang serta masih kurangnya pengalaman. ${ }^{9}$ Kebanyakan responden yang lebih tua mengaku sudah sering datang berobat ke dokter gigi di poli maupun praktek pribadi; oleh karena itu mereka sudah mengetahui kinerja serta prosedur yang dilakukan oleh petugas kesehatan yaitu dokter gigi maupun perawat gigi.

Pada penelitian ini didapatkan bahwa responden berjenis kelamin laki-laki yang mengalami kecemasan hanya sebesar $50,0 \%$ dengan kategori tingkat kecemasan ringan, sedangkan responden berjenis kelamin perempuan yang mengalami 
kecemasan yaitu sebesar $87,5 \%$, dengan tingkat kecemasan kategori ringan 31,2\% dan tingkat kecemasan kategori sedang $56,3 \%$ (Tabel 5). Data tersebut memperlihatkan bahwa tingkat kecemasan lebih tinggi terjadi pada responden berjenis kelamin perempuan dibandingkan dengan yang berjenis kelamin laki-laki. Hasil uji $t$ tidak berpasangan menunjukkan bahwa terdapat perbedaan bermakna antara tingkat kecemasan berdasarkan jenis kelamin pada tindakan penumpatan gigi $(\mathrm{p}=0,000 \leq 0,05)$. Penelitian ini juga didukung oleh studi yang dilakukan oleh Yildirim et $\mathrm{al}^{10} \mathrm{di}$ Diyarbakır, Turkey, Carlsson et $\mathrm{al}^{11} \mathrm{di}$ Swedia, dan Bachri et al ${ }^{12}$ di Jember yang melaporkan bahwa kecemasan gigi secara bermakna lebih tinggi pada jenis kelamin perempuan daripada jenis kelamin laki-laki. Hal ini dikarenakan perempuan mempunyai emosi yang lebih peka yang akan memengaruhi perasaan cemasnya. ${ }^{9}$

Berdasarkan simpulan hasil wawancara dari tiga bagian pertanyaan yang ada pada kuesioner, pada bagian pertama responden yang mengalami kecemasan sebelum tindakan (pada saat di ruang tunggu), mengatakan merasa cemas karena memikirkan hal-hal buruk yang nanti akan terjadi pada saat tindakan misalnya terjadi kegagalan dalam perawatan ataupun kesalahan teknis pada saat operator mengerjakan tumpatan. Pada bagian kedua yaitu sebelum dilakukan tindakan (di dalam ruangan), sampel cenderung merasa cemas saat melihat alat-alat operator dan takut jika alat-alat itu bisa membuatnya terluka. Kemudian pada bagian ketiga yaitu setelah dilakukan tindakan (di dalam ruangan), responden mengeluhkan takut mendengar suara bur yang kencang dan memikirkan jika bur tersebut bisa terkena lidah dan gigi sekitarnya.

\section{SIMPULAN}

Berdasarkan hasil penelitian ini dapat disimpulkan bahwa gambaran tingkat kecemasan yang paling banyak ditemukan yaitu kecemasan kategori ringan dan pada jenis kelamin perempuan. Terdapat perbedaan tingkat kecemasan laki-laki dan perempuan pada tindakan penumpatan gigi.

Untuk menangani kecemasan dalam perawatan gigi dan mulut penting adanya usaha promosi kesehatan gigi dan mulut agar masyarakat lebih mengenal dan mengetahui bahwa perawatan gigi dan mulut sebenarnya tidak menakutkan seperti yang mereka bayangkan.

Bagi operator, perlu memahami cara mengatasi kecemasan pasien agar dapat menenangkan pasien sehingga mampu menurunkan tingkat kecemasan pasien.

Limitasi penelitian ini ialah keterbatasan waktu peneliti. Diharapkan adanya penelitian lanjut mengenai tingkat kecemasan berdasarkan jenis kelamin pada tindakan penumpatan gigi di RSGM Unsrat dengan jumlah responden yang lebih banyak atau uji statistik lebih lanjut untuk mendapatkan hasil yang lebih rinci.

\section{DAFTAR PUSTAKA}

1. Badan Penelitian dan Pengembangan Kesehatan. Hasil utama Riskesdas 2018. Jakarta: Kemenkes RI, 2018; p.181-207.

2. Setiawan AS. Aplikasi teori belajar sosial dalam penatalaksanaan rasa takut dan cemasan anak pada perawatan gigi. Dent J Majalah Kedokteran Gigi 2014;47(2):87.

3. Kandou LFJ, Anindita PS, Mawa MAC. Gambaran tingkat kecemasan pasien umur dewasa pra tindakan pencabutan gigi di balai pengobatan rumah sakit gigi dan mulut Manado. eG. 2013;1(2).

4. Saatchi M, Abtahi M, Mohammadi G, Mirdamadi M, Sadaat E. The prevalence of dental anxiety and fear in patients refered to Isfahan Dental School, Iran. Dental Research Journal Isfahan. 2015;12(3):251.

5. Koleoso ON, Osinowo HO, Akhigbe KO. The role of relaxation therapy and cranial ekectrotherapy stimulation in the management of dental anxiety in Nigeria. IOSR J Dent Med Science. 2013;10(4):51-7.

6. Prihastari L, Ronal A, Octavian M. Gambaran status ketakutan dan kecemasan terhadap perawatan gigi di Wilayah Administrasi Kepulauan Seribu. 
Odonto Dental Journal. 2018; 5(2):119.

7. Shresta A, Rimal J, Rao A, Sequeira PS, Doshi D. Dental anxiety among patient visiting a teaching dental hospital in Manglore, India. Journal of Nepal Dental Association. 2009;10(1):12-5.

8. Boky H, Mariati NW, Maryono J. Gambaran tingkat kecemasan pasien dewasa terhadap tindakan pencabutan gigi di Puskesmas Bahu Kecamatan Malalayang Kota Manado. eG. 2013:1(2).

9. Sadock BJ, Sadock VA. Kaplan \& Sadock Buku Ajar Psikiatri Klinis (2nd ed). Alih bahasa: Profitasari, Nisa TM. Jakarta: EGC, 2010; p.230-95.

10. Yildirim TT, Dundar S, Bozoglan A, Karaman T, Dildes N, Kaya FA, et al. Is there a relation between dental anxiety, fear and general psychological status? Yarbakhir Turkey. 2017;5(4):57.

11. Carlsson V, Hakeberg M, Boman UW. Associations between dental anxiety, sense of coherence, oral health-related quality of life and health behavior a national Swedish cross-sectional survey. BMC Oral Health. 2015; 15(5):213-15.

12. Bachri S, Cholid Z, Rochim A. Perbedaan tingkat kecemasan pasien berdasarkan usia, jenis kelamin, tingkat pendidikan dan pengalaman pencabutan gigi di RSGM FKG Universitas Jember. eJurnal Pustaka Kesehatan 2017; 5(1):141. 